\title{
Acute effects of alcohol on feedback processing and outcome evaluation during risky decision-making: an ERP study
}

\author{
Anja S. Euser • Catharina S. van Meel • \\ Michelle Snelleman • Ingmar H. A. Franken
}

Received: 11 January 2011 / Accepted: 11 March 2011 /Published online: 8 April 2011

(C) The Author(s) 2011. This article is published with open access at Springerlink.com

\begin{abstract}
Rationale Although risky decision-making is one of the hallmarks of alcohol use disorders, relatively little is known about the acute psychopharmacological effects of alcohol on decision-making processes.

Objective The present study investigated the acute effects of alcohol on neural mechanisms underlying feedback processing and outcome evaluation during risky decisionmaking, using event-related brain potentials (ERPs).

Methods ERPs elicited by positive and negative feedback were recorded during performance of a modified version of the Balloon Analogue Risk Task in male participants receiving either a moderate dose of alcohol $(0.65 \mathrm{~g} / \mathrm{kg}$ alcohol; $n=32)$ or a non-alcoholic placebo beverage $(n=32)$.
\end{abstract}

\author{
A. S. Euser $(\bowtie)$ \\ Institute of Psychology, Erasmus University Rotterdam, \\ Woudestein T12-59, P.O. Box 1738, 3000 DR Rotterdam, \\ the Netherlands \\ e-mail: euser@fsw.eur.nl \\ C. S. van Meel \\ Institute of Psychology, Erasmus University Rotterdam, \\ Woudestein T12-44, P.O. Box 1738, 3000 DR Rotterdam, \\ the Netherlands \\ M. Snelleman \\ Institute of Psychology, Erasmus University Rotterdam, \\ Woudestein, P.O. Box 1738, 3000 DR Rotterdam, the Netherlands
}

I. H. A. Franken

Institute of Psychology, Erasmus University Rotterdam, Woudestein T13-12, P.O. Box 1738, 3000 DR Rotterdam, the Netherlands

A. S. Euser

Department of Child and Adolescent Psychiatry,

Erasmus Medical Center Rotterdam,

Rotterdam, the Netherlands
Results Overall, there was no significant difference in the mean number of pumps between the alcohol and the placebo condition. However, when analyzing over time, it was found that the alcohol group made more riskier choices at the beginning of the task than the placebo group. ERPs demonstrated that alcohol consumption did not affect early processing of negative feedback, indexed by the feedback-related negativity. By contrast, alcoholintoxicated individuals showed significantly reduced P300 amplitudes in response to negative feedback as compared to sober controls, suggesting that more elaborate evaluation to losses was significantly diminished.

Conclusions These results suggest that alcohol consumption does not influence the ability to rapidly evaluate feedback valence, but rather the ability to assign sufficient attention to further process motivationally salient outcomes. Blunted P300 amplitudes may reflect poor integration of feedback across trials, particularly adverse ones. Consequently, alcohol may keep people from effectively predicting the probability of future gains and losses based on their reinforcement history.

Keywords Alcohol $\cdot$ Risk taking $\cdot$ Decision-making · Event-related potentials $\cdot$ Feedback-related negativity . P300 - Balloon analogue risk task

Risk-taking is an important component of decision-making that has gathered much attention in the study of substance use disorders. For adaptive behavior, making decisions in the face of uncertainty (risk) is of primary importance. Humans often require feedback from the environment in order to evaluate the potential consequences of their actions. For adaptive decision-making, it is necessary to determine the positive and negative outcomes rapidly to guide current as well as future actions by keeping us engaged in beneficial behaviors. Disruption of this process 
may produce risk-prone behavior, where choice is driven by the positive outcomes (typically the more rewarding options), in spite of possible disadvantageous consequences or punishments (Bechara et al. 1994; Fishbein et al. 2005).

By using gambling or decision-making tasks, several studies demonstrated impaired decision-making processes in alcohol-dependent patients with a bias toward riskier choices. Chronic alcoholics recurrently make decisions favoring larger immediate rewards even in the face of mounting negative long-term consequences (Mazas et al. 2000; Bickel and Marsch 2001; Cantrell et al. 2008; Miranda et al. 2009). It has been hypothesized that substance users may be less sensitive to the negative outcomes of their actions (Bechara et al. 1994, 2002) and are less able to use negative feedback to guide and adjust ongoing behavior (Bechara et al. 2002), suggesting a deficient feedback processing system (Kamarajan et al. 2010). However, despite an abundance of data linking alcohol use disorders to impaired decision-making, far less is known about the acute psychopharmacological effects of alcohol on decision-making processes.

The acute effects of alcohol are well known for their disinhibiting properties, and ample evidence indicates strong associations between alcohol consumption and various forms of risky behavior, such as aggression, crime, violence, highrisk sexual activity, dangerous driving patterns, and other substance use (e.g., Taylor and Chermack 1993; Lau et al. 1995; Halpern-Felsher et al. 1996; White 1997; Cooper 2002; Richardson and Budd 2003; Calhoun et al. 2004; Shuper et al. 2009). However, despite the phenomenological evidence linking alcohol to maladaptive forms of risk-taking behavior, results of laboratory studies that have investigated the acute effects of alcohol on decision-making processesparticularly in the context of uncertainty (risk) - have been heterogeneous. Several studies have shown that alcohol given acutely impairs decision-making (Ridderinkhof et al. 2002; Lane et al. 2004; George et al. 2005). Lane et al. (2004), for example, demonstrated that healthy participants, when alcohol-intoxicated and presented with a choice between risky and non-risky response options, showed a shift towards the risky options, even though this eventually resulted in more losses. In contrast, other studies have found that alcohol intoxication does not always increase risk-taking (Breslin et al. 1999) and may even lead to more cautious decision-making (Ortner et al. 2003). More recently, Balodis et al. (2006) suggested that individual factors moderate the relation between risky decision-making and alcohol use. It is in fact somewhat paradoxical that direct effects of alcohol on risk-taking and decision-making skills have been difficult to observe in laboratory settings, particularly given the frequently observed association between alcohol and risktaking behaviors outside the laboratory.
In order to investigate this issue in further detail, it would be useful to additionally measure neural responses. Electroencephalographic (EEG) research using eventrelated brain potentials (ERPs) may be more sensitive to subtle processing differences between alcohol intoxicated individuals and sober controls than the behavioral measures employed in previous studies. Whereas behavioral measures are an indirect index of mental processes since they rely on motor responses, EEG is arguably a more direct index of these processes. In addition, ERPs to positive (i.e., gains) and negative feedback stimuli (i.e., losses) may provide useful data on both the timing and the neural substrates of feedback processing. Such psychophysiological data may serve as converging operations that supplement behavioral data to advance our understanding of the mechanisms underlying feedback processing and outcome evaluation during risky decisionmaking. Two major ERP components have been described that are particularly sensitive to feedback: the feedbackrelated negativity [FRN, also known as the medial-frontal negativity (MFN)], and the feedback-related P300. The FRN is a negative deflection at fronto-central recording sites that reaches its maximum between 200 and $300 \mathrm{~ms}$ post-onset of feedback stimulus. It is larger following the presentation of negative feedback associated with unfavorable outcomes (e.g., monetary losses) than for positive feedback (e.g., Gehring and Willoughby 2002; Luu et al. 2003; Nieuwenhuis et al. 2004; Hajcak et al. 2005, 2006; Sato et al. 2005; van Meel et al. 2005; Yeung et al. 2005; Holroyd et al. 2006; Holroyd and Krigolson 2007). The FRN reflects an early, rapid evaluation of the affective or motivational impact of outcome events and its amplitude is related to the simple bad versus good appraisal of feedback (Yeung et al. 2004). On the other hand, a subsequent component, the feedback-related P300 amplitude, seems to reflect a later, attention-sensitive, more elaborated appraisal of outcome evaluation, in which factors that affect the allocation of attentional resources come into play in a topdown controlled manner (Sato et al. 2005; Goyer et al. 2008; Christie and Tata 2009; Wu and Zhou 2009; Leng and Zhou 2010; Zhou et al. 2010). P300 is the most positive peak in the 300-600 ms post-onset of feedback and has been shown to be sensitive to various aspects of outcome, including the magnitude and the valence of reward (Wu and Zhou 2009). Previous studies found differential effects of positive and negative outcomes on P300 amplitudes (e.g., Hajcak et al. 2005, 2007; Martin and Potts 2009). Given that the P300 amplitude is generally believed to be associated with processes of attentional allocation and to high-level motivational evaluation (e.g., Johnson 1986; Polich and Criado 2006), P300 amplitudes probably reflect the evaluation of the functional significance of feedback stimuli. 
To our knowledge, there have been three ERP studies reported on feedback processing or outcome evaluation in individuals diagnosed with alcohol dependence. Porjesz et al. (1987) demonstrated decreased P300 amplitudes in response to incentive stimuli in abstinent alcoholics. More recently, using the Balloon Analogue Risk Task (BART) which measures risk-taking propensity, Fein and Chang (2008) reported smaller FRN amplitudes and larger P300 amplitudes in response to negative feedback in treatmentnaive alcoholics with a greater family history density of alcohol problems. Additionally, Kamarajan et al. (2010) demonstrated that alcoholics had significantly lower P300 amplitudes during both loss and gain feedback as compared to healthy controls. Although these results are sometimes conflicting and seem task dependent, these findings lend support to the notion that alcoholics display an abnormal feedback processing. However, no ERP studies investigating the acute effects of alcohol on feedback processing during risky decision-making have been reported.

The present study used ERPs to investigate the acute psychopharmacological effects of alcohol on the neural mechanisms underlying feedback processing and outcome evaluation during a modified version of the BART (Lejuez et al. 2002; Pleskac et al. 2008). The BART is a sensitive measure of risky decision-making, which involves inflating a simulated balloon on a computer screen that could either grow larger or explode. Participants accumulate money each time they pump up the balloon and during the task they are repeatedly given the option to discontinue inflating and save the money accumulated to that point or to continue pumping. However, each pump also carries the risk that the balloon will explode, leading the participants to lose all the money from that balloon. Behavioral studies have been demonstrated that the mean number of presses on trials when participants did not burst the balloon (increased risk-taking) is strongly related with the selfreported occurrence of risk behaviors (e.g., substance use, cigarette smoking, gambling, delinquency, and unprotected sexual inter-course; Lejuez et al. 2002, 2003a, b, 2004, 2005; Aklin et al. 2005; Hopko et al. 2006), as well as with scores on risk-related personality constructs (e.g., impulsivity and sensation seeking; Lejuez et al. 2002; Hunt et al. 2005; Vigil-Colet et al. 2007). In the present study, however, we used an automatic response mode version (automatic BART) as described in Pleskac et al. (2008). Instead of sequentially pumping the balloon, this automatic BART requires participants to type the target number of pumps (corresponding to how much risk) they wish to perform at the beginning of each trial. Once this value is accepted, participants watch the balloon as it automatically inflates until either the stated number of pumps is reached or the balloon explodes. This automatic version has some advantages over the standard BART. The main advantage is that the scores on the automatic BART are not biased, as is the case with the standard BART (Pleskac et al. 2008). In the standard BART, and more generally in all sequential risk-taking tasks, how many risks a participant would have taken on trials that end in a loss is unobserved. Consequently, the standard BART uses the adjusted average number of pumps as a risk propensity measure, which is the average number of pumps excluding balloons that exploded (Lejuez et al. 2002; Pleskac et al. 2008). This score, however, is biased because it is based on the false assumption that trials that end in an explosion are independent from the behavior of the participant. In contrast, the automatic response mode version makes participant's intended number of responses on each trial observable. As a result, the average target score can be used as behavioral statistic, which is the average number of pumps that participants would have executed on all trials regardless of whether the balloon has exploded or not, thereby increasing the reliability of the data. Consideration of the adjusted average score excludes from the calculation to those trials with higher numbers of target pumps, resulting in a lower average adjusted score than when the target score is used. Hence, the target score tends to be a more reliable and unbiased estimator of risk taking propensity. Other advantages of the automatic BART include that the task is less time consuming and requires less motor activity, which is particularly important in psychophysiological research.

The aim of the current investigation was three-fold. First, because of the clear relationship between alcohol consumption and risky behavior often observed outside the laboratory, it was hypothesized that alcohol-intoxicated individuals would make more risky, disadvantageous decisions during the BART than individuals in the placebo group. Second, we hypothesized that impaired and risky decision-making in alcohol-intoxicated individuals would be driven by hyposensitivity to negative feedback, with reduced FRN and P300 amplitudes indicating decreased sensitivity. Subsequently, we expected risk-taking during the BART to be negatively related to the FRN and P300 amplitude. Finally, we sought to determine whether risky decision-making during the BART was moderated by personality factors that may be directly related to performance on decision-making tasks using feedback, including impulsivity, sensation seeking, and sensitivity of the behavioral activation system (BAS).

\section{Methods}

Participants

Sixty-four healthy males between the age of 18 and 25 (mean age $=20.51$ years, $\mathrm{SD}=1.99$ ) were recruited to participate in 
this study. Participants were recruited from the undergraduate population of the Erasmus University in Rotterdam and by posting weblogs on social network sites. Screening measures were conducted to determine medical history and took place by telephone. Inclusion criteria were the absence of a current medical, neurological, or psychiatric condition, and no current use of medication during the past 4 weeks before the experimental session. Participants were not included in the study if they had a self-reported history of alcohol-related problems. The median frequency of drinking days was 9 to 11 days each month, and the median quantity of drinks on each occasion was six glasses. The median age of drinking onset was between 14 and 15 years.

Participants were randomly assigned to an alcohol $(n=32)$ or placebo group $(n=32)$. The alcohol and placebo participants were matched in terms of age. Mean age of the alcohol group was 20.39 years $(\mathrm{SD}=2.01)$ and mean age of the placebo group was 20.63 years $(\mathrm{SD}=1.99)$. There were no significant group differences on self-reported habitual drinking patterns [total score of the quantity-frequencyvariability (QFV) index of drinking patterns] and age of onset of alcohol use [ $t$ 's $(59)<-1.27]$. Furthermore, no significant group differences were found in self-reported measures of impulsiveness (BIS-11), sensation seeking (BSSS), and reward/punishment sensitivity (BIS/BAS subscales) $[t$ 's $(59)<1.12]$.

\section{Alcohol dose and beverage administration}

Participants in the alcohol group received a moderate dose of alcohol $(0.65 \mathrm{~g} / \mathrm{kg})$ in a beverage containing one part of vodka ( $40 \%$ of alcohol) and two parts of orange juice, divided equally over two glasses. Participants in the placebo group received a non-alcoholic beverage $(0.00 \mathrm{~g} / \mathrm{kg}$ alcohol $)$, consisting of one part of tonic and two parts of orange juice, which was served in the same manner. To induce an alcohol odor in the placebo group, $4 \mathrm{ml}$ of vodka (1\%) was applied on the glasses and floated on top of the beverages. Participants in both groups were told they would receive either a high or a low dose of alcohol. All participants had $2 \mathrm{~min}$ to finish each glass through a straw. The two glasses were served 4 min apart (Weafer and Fillmore 2008).

Subjective effects of drinking were measured $25 \mathrm{~min}$ after drinking and immediately following the testing period. Breath samples to measure the blood alcohol concentration (BAC) were collected at five moments during the study using 6,510 Alcohol test (Dräger; Lübeck, Germany) breath analyzer equipment: before alcohol administration, and 25, 55, and 80 min after beverage administration (immediately preceding and immediately following the testing period), and approximately $2 \mathrm{~h}$ after beverage administration. The peak BAC was expected to occur about $60 \mathrm{~min}$ after drinking (Fillmore and Vogel-Sprott 1998; Weafer and Fillmore 2008).
Subjective ratings

Brief sensation seeking scale (BSSS) The Brief Sensation Seeking Scale (BSSS; Hoyle et al. 2002) is a short (eight items) self-report measure and assesses trait sensation seeking suitable for use with adolescents and young adults. The eight items are scored on a five-point Likert scale, with the points labeled as follows: strongly disagree, disagree, neither disagree nor agree, agree, and strongly agree. We used the total score as measure for sensation seeking. Higher scores on this scale represent higher trait sensation seeking in participants. Psychometric properties of the BSSS are good and hold up across age, sex, and ethnic categories (Hoyle et al. 2002).

Barratt impulsiveness scale-11 (BIS-11) The Barratt Impulsiveness Scale-11 (BIS-11; Patton et al. 1995) is a selfreport measure of impulsiveness and consists of 30 items; the items are answered on a four-point scale (rarely/never, occasionally, often, and almost always/always). For the present study, we used the total score. This summed score of all items determines the degree of impulsiveness, the higher the summed score, the higher the level of impulsiveness of the participant. The BIS-11 has good psychometric properties (Patton et al. 1995).

Behavioral inhibition system and behavioral activation system scales (BIS/BAS scales) The BIS/BAS scales (Carver and White 1994) are presented as a self-report questionnaire, which measures the behavioral approach system (BAS), and the behavioral inhibition system (BIS). BAS measures sensitivity to reward, and BIS measures sensitivity to punishment. The BIS/BAS scales consist of 24 items which can be divided into four subscales: BAS-fun seeking, BASreward responsiveness, BAS-drive, and BIS. Also, BAStotal score can be computed. Items are scored on a four-point scale with the following labels: completely agree, agree, disagree, and completely disagree. The psychometric properties for the Dutch version of the BIS/BAS scales are satisfactory (Franken et al. 2005).

Habitual drinking patterns (QFV-index) The QFV-index (Lemmens et al. 1992; Meerkerk et al. 1999) was used to measure habitual drinking patterns. In this questionnaire, three items are employed to determine the drinking quantity (number of glasses), frequency (drinking days), and variability (binge drinking) during the last 6 months. Furthermore, one question was added to determine the age of onset of drinking.

Subjective alcohol effects Throughout the study, participants completed several self-report ratings to assess the subjective effects of the beverage. First, participants indicated on a five-point Likert scale how many effects 
they experienced from the beverage (i.e., magnitude of effects; $1=$ no effect at all, 2=a little effect, 3=moderate effect, $4=$ relatively much effect, $5=$ strong effect). Second, a Visual Analogue Scale (VAS) was used to examine their current subjective experience of pleasantness of the effect of the consumed beverage.

\section{Balloon analogue risk task (BART)}

The automatic version of the BART was used to assess risktaking behavior (Pleskac et al. 2008). The task was presented on a computer screen which included a small balloon, accompanied by a dial of numbers (0-9), a reset button, and three permanent displays listing the current reward/loss magnitude of the balloon ("pumps selected"), the total money earned ("total earned"), and the money earned on the last balloon ("last balloon"). Participants were told that they had to pump up 60 separate balloons (i.e., 60 trials). At the beginning of each trial, the participant had to determine for himself how many times this specific balloon should be pumped in order to get the best score. The number of pumps was selected by the participant using a mouse; the participants clicked on the numbers showed on the screen. Each balloon had an inflation time of $3 \mathrm{~s}$. After the inflation time, there were two possible outcomes: the balloon would still be whole and money was earned (i.e., positive feedback), or the balloon was pumped past its individual explosion point, the balloon popped and hence, the money was lost (i.e., negative feedback). After the feedback of each balloon (money collection or explosion), a new un-inflated balloon appeared on the screen until a total of 60 balloon pumps was completed.

The maximum number of pumps possible was set to 128 for each balloon with an explosion a priori equally likely to occur on any given pump subject to the constraint that within each sequence of ten balloons the average explosion point was on pump 64. All participants were presented the same balloons in the same order to limit extraneous variability. A balloon that did not explode was encoded as a "positive feedback" trial; a balloon that exploded was encoded as a "negative feedback" trial. The two types of feedback were used for analyses of FRN and P300 activity during completion of the BART.

\section{Procedure}

Interested volunteers responded to study advertisements and weblogs on social network sites by contact us by email or telephone. A screening by telephone was conducted during which students received information about the experimental procedure and in order to determine eligibility for participation. Eligible volunteers then made appoint- ments to come to the Erasmus Behavioral Lab (Erasmus University Rotterdam) for one experimental session of approximately $2 \mathrm{~h}$. All participants were instructed to abstain from food and cigarette use $2 \mathrm{~h}$ before testing, to abstain from caffeine on the testing day, as well as to refrain from consuming alcoholic beverages or any psychoactive drugs or medications for $24 \mathrm{~h}$ before the experimental session. At arrival at the laboratory (all between noon and 6 p.m.), participants signed informed consent, they were weighed, and initial breath alcohol level was assessed to ensure that they were sober before onset of the experiment. None of the participants was positive on this test. Hereafter, participants completed the self-report questionnaires. Subsequently, the alcohol or placebo beverage was administered and subjects were seated on a comfortable chair in a light- and sound-attenuated room. After the EEG electrodes were attached (which took $25 \mathrm{~min}$ ), BAC was monitored for the second time. First, participants conducted a cognitive task (go-nogo) lasting $20 \mathrm{~min}$ (not reported in this paper). Then they completed a brief subjective measure of the magnitude and the pleasantness of the alcohol effects and BAC level was monitored for the third time. Approximately 50 min after alcohol administration, the BART was administered to measure risky decision-making and feedback processing. Participants were told they were going to pump up 60 balloons on the computer screen. The goal was to obtain as much points as possible. As an additional incentive, participants were told that the participant who would obtain the highest score of all would receive an extra reward of $€ 100$. After completion of the BART, participants were disconnected from the EEG. They were given a final subjective measure of alcohol effects and BAC level was measured for the fourth time. Participants were then instructed to remain in the university building and had to go to the refectory to eat and drink something. After $45 \mathrm{~min}$ (i.e., $2 \mathrm{~h}$ after beverage administration), participants had to return to the laboratory to monitor their final $\mathrm{BAC}$ and participants were allowed to leave once their BAC fell to $20 \mathrm{mg} / 100 \mathrm{ml}$ or below. All participants received a small financial reward or course credits for their participation, and they were instructed not to drive a vehicle after the experiment. The study was conducted in accordance with the Declaration of Helsinki and approved by the ethics committee of the Institute of Psychology of the Erasmus University Rotterdam.

Electroencephalogram (EEG) acquisition and analysis

The EEG was recorded with BioSemi Active-Two using 34 scalp sites (10-10 system, and two additional electrodes at $\mathrm{FCz}$ and $\mathrm{CPz}$ ) with $\mathrm{Ag} / \mathrm{AgCl}$ active electrodes mounted in an elastic cap. Furthermore, six additional electrodes were attached. Two electrodes were attached to the left and right 
mastoids as reference electrodes. To record ocular movement and to be able to correct for ocular artifact, two electrodes were placed next to each eye for horizontal electrooculogram (HEOG) and two electrodes were placed above and below the left eye for vertical electrooculogram (VEOG). Online signals were recorded with a low-pass filter of $134 \mathrm{~Hz}$. All signals were digitized with a sample rate of $512 \mathrm{~Hz}$ and 24-bit $\mathrm{A} / \mathrm{D}$ conversion.

Data were off-line referenced to mathematically linked mastoids. Because we were interested in FRN as well as in P300, EEG data were filtered offline with different parameters, which is in line with previous literature (Luu et al. 2003; Donkers et al. 2005; Wu and Zhou 2009). For the FRN, data were filtered using a 2 to $12 \mathrm{~Hz}$ bandpass filter (Donkers et al. 2005). A conventional wideband filter of 0.10 to $30 \mathrm{~Hz}$ (phase shift-free Butterworth filters; $24 \mathrm{~dB} /$ octave slope) was used to investigate the feedback related P300 amplitude. After ocular correction (Gratton et al. 1983), feedback-locked epochs were created from positive (balloon inflated; money gained) and negative (balloon popped; money lost) feedback and were baseline corrected using the $200-\mathrm{ms}$ pre-stimulus interval. The length of the epochs was $1,000 \mathrm{~ms}(200 \mathrm{~ms}$ pre-stimulus until $800 \mathrm{~ms}$ post-stimulus). Epochs including out of range voltages $( \pm 75 \mu \mathrm{V})$ were rejected as artifacts and were excluded from further processing. If $50 \%$ or more of the epochs of a participant contained artifacts, this participant was excluded from further analyses. As a result, three participants were rejected from further analyses, two in the placebo group and one in the alcohol group. The mean number of included negative feedback trials was 25.02 (SE $=0.75$ ), and mean number of positive feedback trials was $29.38(\mathrm{SE}=0.60)$. Epochs locked to positive and negative feedback were averaged separately for artifact-free trials at each scalp site, producing one average waveform per feedback condition per subject. All epochs, across balloons in the entire test block from the start of the procedure, were included in the average. A finer grain analysis of the data separated across the three 20-trial blocks of the BART (as was done for the behavioral measure of risk-taking) was not appropriate because this resulted in too few epochs for each average.

Derived from inspecting the grand average and individual subject data, the FRN component was identified as the most negative amplitude within a 200 to $300 \mathrm{~ms}$ window following feedback onset. The P300 component was defined as the maximum amplitude within 300 to $400 \mathrm{~ms}$ following the FRN peak. Statistical analyses for both components were done on fronto-central electrodes $\mathrm{Fz}, \mathrm{FCz}$, and $\mathrm{Cz}$.

Statistical analysis

Demographic differences between groups with respect to age and scores on the subjective self-report ratings were assessed with independent samples $t$ tests. Independent samples $t$ tests were also conducted to assess differences in BAC levels before and after administration of the BART.

For the behavioral measure of risk-taking, we analyzed the mean target number of pumps across balloons (i.e., BART score) as the primary independent variable. The effect of alcohol was assessed with independent samples $t$ tests. Moreover, we stratified the BART into three different blocks, corresponding to the number of pumps for each group of 20 of the 60 balloons. This measure reveals whether there was a strategy shift during the task as a function of Group (alcohol versus placebo) and was assessed with a $3 \times 2$ repeated measures analysis of variance (ANOVA), with Block (pumps 1-20, pumps 21-40, and pumps 41-60) as within-subject factor and Group (alcohol versus placebo) as between-subject factor.

For peak FRN and P300 amplitudes, a repeated measures ANOVA was performed with Group (alcohol versus placebo) as between-subject factor and Feedback (positive versus negative) and Electrode Site (three midline sites- $-\mathrm{Fz}, \mathrm{FCz}$, and $\mathrm{Cz}$ ) as within-subject factors. To control the increase in type I error, Greenhouse-Geisser corrections were adopted where appropriate. Post hoc tests were performed using the Bonferroni correction with a significance level of $p<0.05$.

Spearman correlation coefficients were used to find associations between risk-taking behavior during the BART (mean number of pumps), feedback-related ERPs, and ratings of the personality self-report questionnaires in both groups. For all correlation analysis, FRN and P300 amplitudes were taken from the difference waveforms (defined as the maximum amplitude of the negative waveform 200 to $300 \mathrm{~ms}$ following feedback onset for the FRN and the maximum amplitude of the positive waveform 300 to $400 \mathrm{~ms}$ following feedback onset for P300).

\section{Results}

Blood alcohol concentration and subjective alcohol effects

No detectable BACs were observed in the placebo group (i.e., 0.00\%). In the alcohol group, the mean BAC level 25 min after initiation of drinking alcohol (BAC2) was $0.72 \%$ o $(\mathrm{SD}=0.18$; range $=0.39-1.12 \%$ ). Mean $\mathrm{BAC}$ level before the start of the BART (BAC3; approximately $50 \mathrm{~min}$ after initiation of drinking) was $0.77 \%$ o $(\mathrm{SD}=0.13$; range $=$ $0.52-0.97 \%$ ) and mean BAC level a further 15 min later (BAC4), after completion of the BART, was $0.72 \%$ ( $\mathrm{SD}=$ 0.11 ; range $=0.48-0.93 \%$ ). As expected, the peak BAC occurred about 60 min after drinking (see Fig. 1).

With respect to the subjective experience of the effects of the drinks, there was a significant difference $[t(59)=7.54$, 


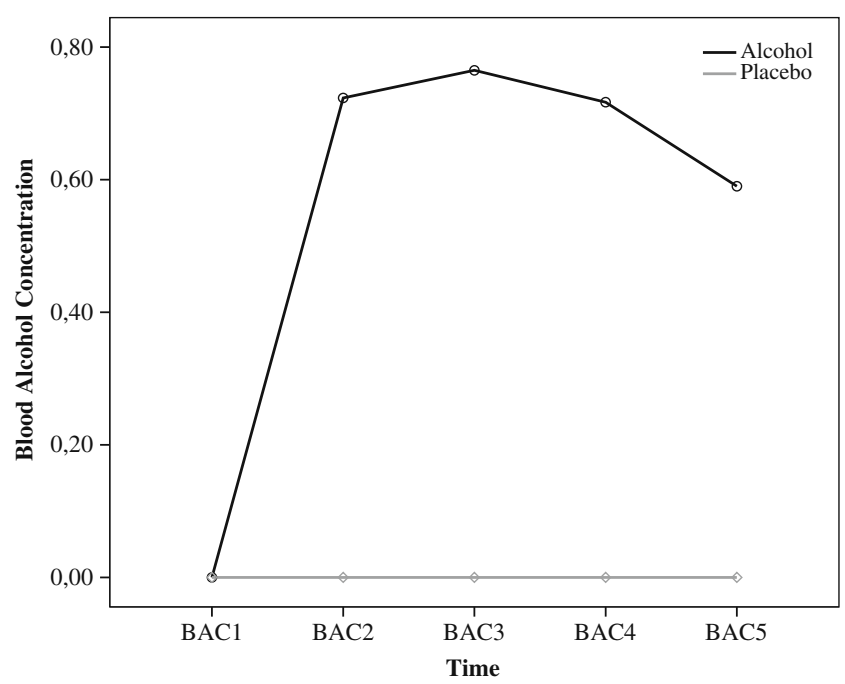

Fig. 1 Breath alcohol concentration $(B A C)$ for the alcohol and placebo participants. The $Y$-axis represents $\mathrm{BAC}$ as a function of time, with each sample taken before and after each behavioral test session ( $X$-axis)

$p<0.001]$ in mean magnitude of the alcohol effects between the alcohol condition $(M=3.32, \mathrm{SD}=0.95)$ and the placebo condition $(M=1.67, \mathrm{SD}=0.76)$ before administration of the BART, and this difference remained significant after completing the task $[t(59)=6.36, p<0.001]$. Regarding the pleasantness ratings of the effect of the drinks, the alcohol group $(M=68.90, \mathrm{SD}=16.07)$ rated the drink as more pleasant $[t(59)=4.16, p<0.001]$ than the placebo group $(M=49.93, \mathrm{SD}=19.21)$ before administration of the BART. This difference remained statistically significant $[t(59)=2.91, p<0.01]$ after completion of the task. In the alcohol group, no correlations were found between BACs and subjective ratings of the effect ( $r$ 's $<0.25 ; \mathrm{ns})$.

\section{Behavioral results}

Table 1 shows the descriptive statistics for all measures of the BART. Statistical analyses revealed that overall there was no significant difference $[t(59)=-0.41 ; \mathrm{ns}]$ in the mean number of pumps between the alcohol $(M=62.32$,

Table 1 Descriptive statistics for BART measures for the alcohol $(n=31)$ and placebo groups $(n=30)$

\begin{tabular}{llllll}
\hline & \multicolumn{2}{l}{ Alcohol group } & & \multicolumn{2}{l}{ Placebo group } \\
\cline { 2 - 3 } & Mean & SD & & Mean & SD \\
\hline Mean pumps & 62.32 & 9.93 & & 63.19 & 6.27 \\
Pumps 1-20 & 64.92 & 9.58 & & 60.39 & 8.01 \\
Pumps 21-40 & 60.22 & 9.68 & & 63.86 & 8.40 \\
Pumps 41-60 & 61.82 & 12.99 & & 65.06 & 7.16 \\
\hline
\end{tabular}

$\mathrm{SD}=9.93)$ and the placebo condition $(M=63.19 ; \mathrm{SD}=$ 6.27), indicating that, across all blocks, alcohol did not result in altered decision-making. However, a significant Condition $\times$ BART block interaction was found $[F(2,58)=$ $8.30, p<0.001)$. Post hoc analyses for each group separately revealed a significant main effect of block in the alcohol group $[F(2,29)=11.51, p<0.001]$, as well as the placebo group $[F(2,28)=3.13, p<0.05]$. Pairwise comparisons showed that the alcohol group significantly decreased the number of pumps from the first to the second block $(p<0.001)$, while there was no significant change from the second to the third one. The placebo group, by contrast, slowly increased the number of pumps throughout the task, showing a significant increase only between the first and the last block $(p<0.05)$. Furthermore, we found marginally significant between-group differences in trials 1-20: participants in the alcohol group made marginally more risky decisions $(p=0.06)$ during the first 20 trials as compared to the control group. Mean number of pumps for each block of 20 trials, as a function of condition, are depicted in Fig. 2.

Electrophysiological results

\section{Feedback-related negativity}

Mean FRN amplitudes for positive and negative feedback for the three electrode sites $(\mathrm{Fz}, \mathrm{FCz}$, and $\mathrm{Cz})$ are presented in Table 2. The grand averages for the two types of feedback at each electrode site are depicted in Fig. 3 and the topographical distribution of the current source density (CSD) of the FRN for each group and condition is displayed in Fig. 4. Repeated measures ANOVA conducted on peak FRN amplitude revealed a significant main effect

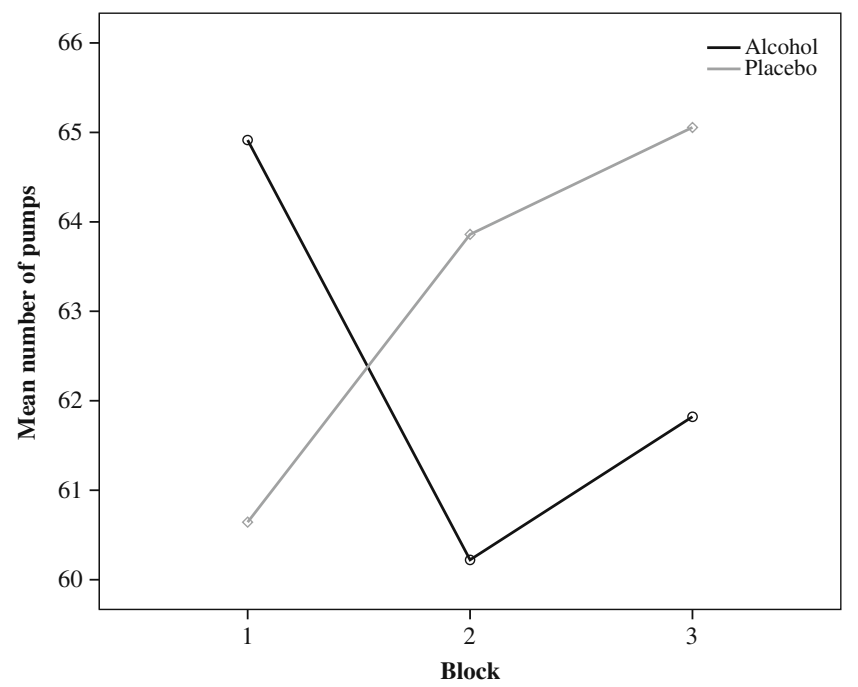

Fig. 2 Mean number of pumps of each block of 20 trials as a function of group 
Table 2 Mean and SD of FRN amplitude for the alcohol $(n=31)$ and placebo group $(n=30)$

\begin{tabular}{llllll}
\hline \multirow{2}{*}{ Feedback } & \multicolumn{2}{l}{ Alcohol group } & & \multicolumn{2}{l}{ Placebo group } \\
\cline { 2 - 3 } \cline { 6 - 6 } & Mean & SD & & Mean & SD \\
\hline Positive & & & & \\
Fz & -2.25 & 2.45 & & -1.74 & 3.81 \\
FCz & -2.20 & 3.18 & & -1.57 & 6.14 \\
Cz & -2.22 & 2.94 & & -1.57 & 4.20 \\
Negative & & & & \\
Fz & -2.86 & 3.49 & & -3.33 & 4.20 \\
FCz & -2.43 & 4.20 & & -3.99 & 5.78 \\
Cz & -2.67 & 3.73 & -3.65 & 5.03 \\
\hline
\end{tabular}

of feedback valence $[F(1,59)=4.89, p<0.05]$. Post hoc test revealed that the FRN was larger for negative feedback indicating loss $(-3.2 \mu \mathrm{V})$ as compared to positive feedback indicating gain $(-1.9 \mu \mathrm{V})$. There was no significant main effect of electrode site $[F(2,58)=0.01, p=0.99]$. Importantly, neither the main effect of group $[F(1,59)=0.07, p=$ $0.80]$ nor the interaction effect of group and feedback valence $[F(1,59)=2.07, p=0.16]$ did reach statistical significance.

\section{Feedback-related P300}

Mean P300 amplitudes for positive and negative feedback for the three electrode sites (Fz, FCz, and $\mathrm{Cz}$ ) are presented in Table 3. The grand averages for the two types of feedback at each electrode site are depicted in Fig. 5 and the topographical distribution of the current source density (CSD) of the P300 amplitude for each group and condition is displayed in Fig. 6. Repeated measures ANOVA conducted on peak P300 amplitude revealed significant main effects of feedback valence $[F(1,59)=55.64, p<$ $0.001]$ and electrode site $[F(2,58)=125.50, p<.001]$. Post hoc tests revealed that $\mathrm{P} 300$ amplitude was larger in response to negative feedback $(24.8 \mu \mathrm{V})$ than to positive feedback $(18.6 \mu \mathrm{V})$. Furthermore, P300 amplitude was largest at $\mathrm{FCz}(24.3 \mu \mathrm{V})$ followed by the amplitude at $\mathrm{Cz}$ and $\mathrm{Fz}(23.1 \mu \mathrm{V}$ and $17.7 \mu \mathrm{V}$, respectively).

The main effect of group was not statistically significant $[F(1,59)=2.83, p=0.10]$. Importantly, we observed a significant interaction effect of group and feedback valence $[F(1,59)=6.16, p<0.05]$. Although there were no $\mathrm{P} 300$ amplitude differences between the alcohol and placebo group in response to positive feedback $(18.0 \mu \mathrm{V}$ versus $19.1 \mu \mathrm{V}, p=0.54$ ), post hoc analyses revealed that, in response to negative feedback, alcohol-intoxicated individuals showed significantly reduced P300 amplitudes as compared to sober controls $(22.1 \mu \mathrm{V}$ versus $27.4 \mu \mathrm{V}$, $p=0.02$ ), indicating a reduced sensitivity for negative feedback in alcohol-intoxicated subjects.

Correlational results

Table 4 shows the correlations between risk-taking behavior during the BART (i.e., the mean number of pumps), feedback-related ERPs, and self-reported personality measures. As can be seen, the amplitude of the FRN in the alcohol group was not correlated with the feedback-related P300 amplitude, which further supports the independence of the two components during feedback processing. In the alcohol group, strong correlations were found between the ERPs and risk-taking behavior. Remarkably, FRN to negative feedback was positively correlated with the mean number of pumps, whereas P300 amplitudes were negatively correlated with risk-taking behavior. These results indicate that in the alcohol group, hyposensitivity for negative feedback as measured with P300, but not FRN, is associated with increased risk-taking. Furthermore, none of the correlations between BART parameters and personality measures were significant, which provide evidence to suggest that a direct psychopharmacological effect of alcohol, rather than individual factors, play an important role in moderating risky decision-making.

In the placebo group, the FRN was negatively correlated with P300 amplitudes. However, ERP responses to feedback were unrelated to risk-taking behavior during the BART. Furthermore, significant correlations were found between BART parameters and personality measures: a negative correlation was found between BAS total score and the mean number of pumps in block 1. Moreover, a strong positive correlation was found between the total impulsivity score and FRN amplitude.

\section{Discussion}

To our knowledge, the present study is the first that investigated the acute psychopharmacological effects of alcohol on the neural mechanisms underlying feedback processing and outcome evaluation during risky decisionmaking while ERPs elicited by gains and losses were recorded. Our results indicate that healthy males under influence of a moderate dose of alcohol $(0.65 \mathrm{~g} / \mathrm{kg}$ alcohol $)$ show unimpaired early processing of feedback information, while showing aberrations in the later stages of outcome evaluation.

On the behavioral level, we found several interesting patterns. Results demonstrated that both groups effectively modified their strategy based on outcomes in the first block of trials. However, while the placebo group started off cautiously during the first block and then increased the 
Fig. 3 Stimulus-locked grand average waveforms (filtered 2-12 Hz) from electrodes $\mathrm{Fz}$, $\mathrm{FCz}$, and $\mathrm{Cz}$ evoked by positive and negative feedback in the BART. Left panel: alcohol group, right panel: placebo group
Alcohol group
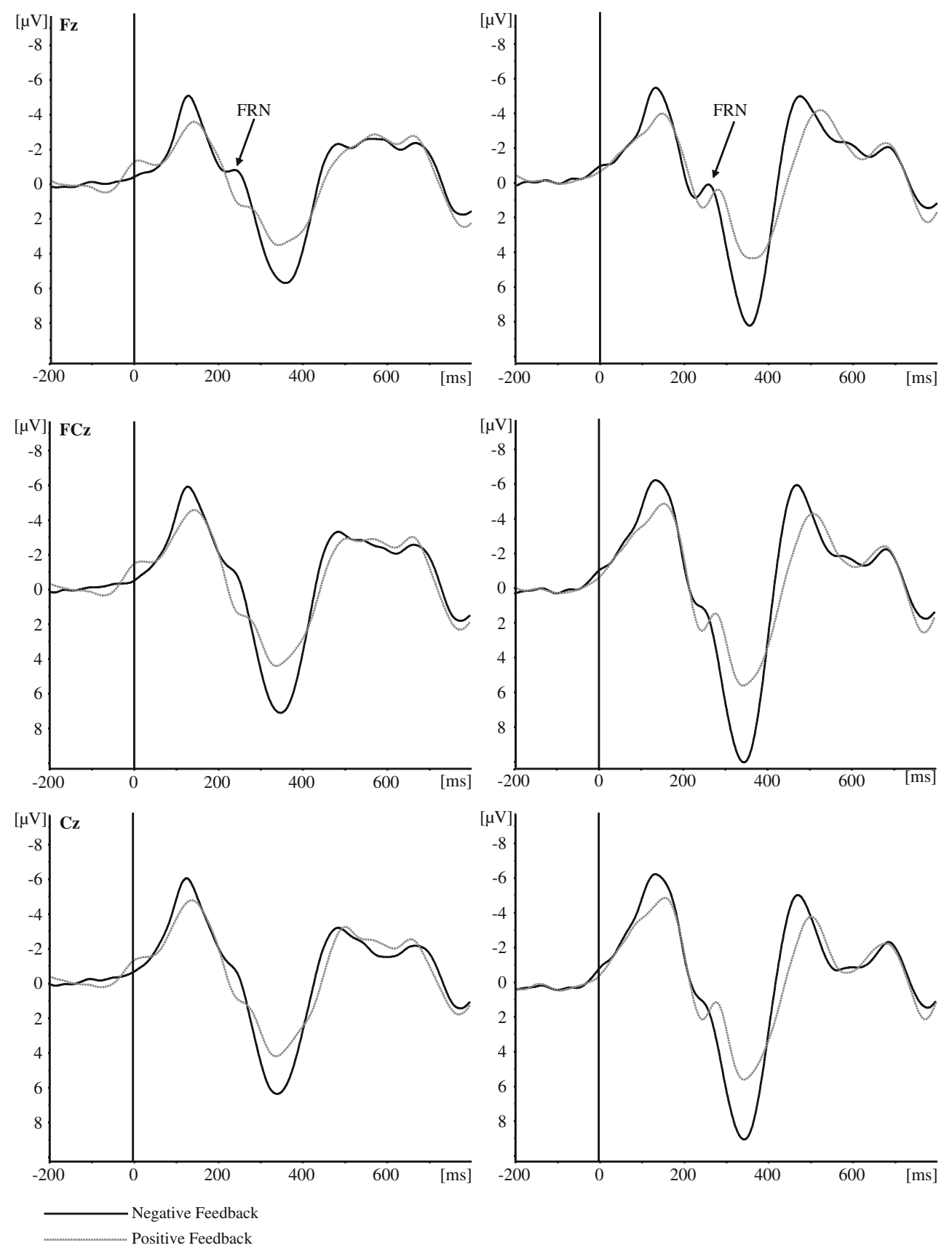

Placebo group

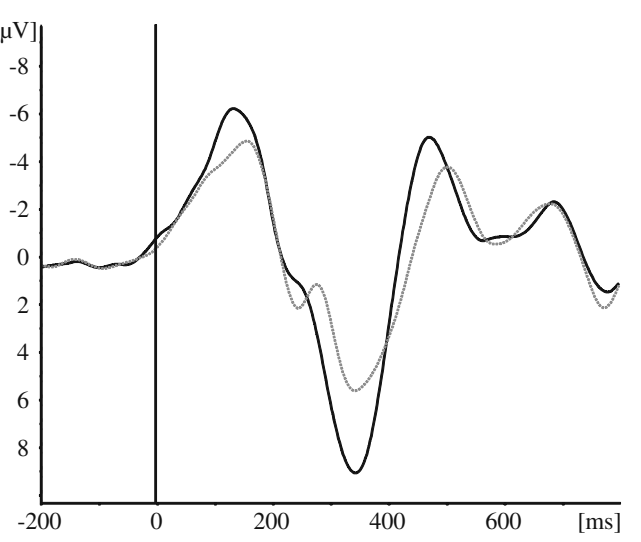

number of risky choices to an optimal level during the remaining blocks, the alcohol group exhibited the opposite strategy. Initially, this group made more risky choices than the placebo group but adopted a safer strategy during the remaining two blocks, arguably after realizing that the initial strategy was not optimal. However, in contrast to the placebo group, the alcohol group did not approach the optimal balance of 64 pumps, but kept on using a less effective strategy. This finding might explain the heterogeneity of results from previous studies, some of whom failed to observe increases in risk-taking after alcohol consump- tion or even reported decreases (Breslin et al. 1999; Ortner et al. 2003). Analyses based on choices across the entire task may have obscured group differences in strategy changes during the tasks in those studies.

Regarding the electrophysiological findings, we found significant FRN and P300 components in the fronto-central region following feedback in a risky decision-making task. Both the amplitude of the FRN and feedback-related P300 amplitude were modulated by the valence of the outcome. FRN and P300 amplitudes were larger in response to negative feedback than to positive feedback. These effects 
Fig. 4 Topographical distribution of the current source density (CSD) of the FRN (200$300 \mathrm{~ms}$ ) associated with losses (i.e., negative feedback; upper row) and gains (i.e., positive feedback; bottom row) for each group
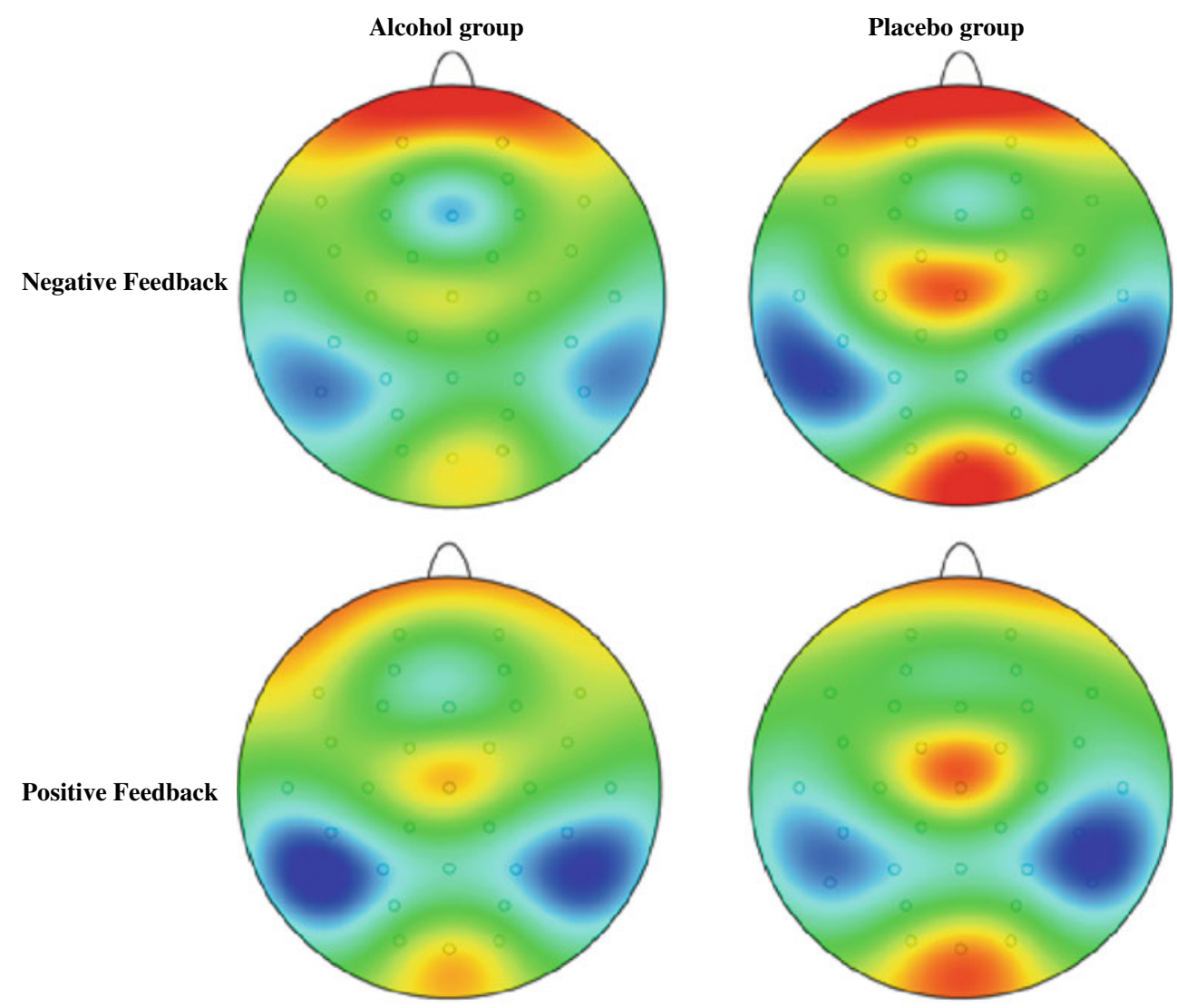

$-8.00 \mu \mathrm{V} / \mathrm{m}^{2}$ are found in previous studies and suggest that overall the task was suitable to elicit robust feedback-related brain potentials in this sample. With respect to the acute effects of alcohol on those feedback processing components, the results revealed differences in early versus later feedback processing: FRN and P300 amplitudes did not show a similar sensitivity to the effect of alcohol. In contrast to our hypothesis, no differences between the alcohol-intoxicated

Table 3 Mean and SD of P300 amplitude for the alcohol $(n=31)$ and placebo group $(n=30)$

\begin{tabular}{lllllr}
\hline \multirow{2}{*}{ Feedback } & \multicolumn{2}{l}{ Alcohol group } & & \multicolumn{2}{l}{ Placebo group } \\
\cline { 2 - 3 } \cline { 5 - 6 } & Mean & SD & & Mean & SD \\
\hline Positive & & & & \\
Fz & 14.53 & 6.63 & & 14.98 & 7.75 \\
FCz & 19.17 & 7.18 & & 20.24 & 8.47 \\
Cz & 20.33 & 6.40 & & 22.20 & 7.62 \\
Negative & & & & \\
Fz & 18.31 & 8.00 & & 22.80 & 9.30 \\
FCz & 23.63 & 8.59 & & 29.39 & 10.62 \\
Cz & 24.48 & 8.30 & 29.98 & 9.82 \\
\hline
\end{tabular}

or placebo group were found on the FRN amplitude, indicating that the neural system supporting the rapid evaluation of unfavorable outcomes was not modulated by alcohol. In line with our hypothesis, feedback-related P300 amplitudes in response to negative feedback (i.e., balloon bursts) were reduced in alcohol-intoxicated individuals as compared to sober controls, and this group difference was absent in response to positive feedback. Hence, our behavioral observations corroborate the ERP results, demonstrating that early feedback processing, as indexed by the FRN, remained intact after alcohol consumption, enabling participants to modify behavior from trial to trial in accordance to feedback. Alcohol-intoxicated participants, in contrast to the participants in the placebo condition, nevertheless failed to achieve the most optimal strategy on the long run. This could be explained by the diminished P300 amplitudes to losses. The P300 is traditionally associated with context updating in working memory. Here, blunted P300 amplitudes may reflect less effective integration of past occurrences of outcomes, particularly penalties, over the course of the task. Consequently, our ERP findings suggest that it is not the ability to rapidly evaluate feedback valence that is influenced by alcohol consumption, but rather the ability to subsequently assign sufficient attention 
Fig. 5 Stimulus-locked grand average waveforms (filtered $0.1-30 \mathrm{~Hz}$ ) from electrodes $\mathrm{Fz}$, $\mathrm{FCz}$, and $\mathrm{Cz}$ evoked by positive and negative feedback in the BART. Left panel: alcohol group, right panel: placebo group
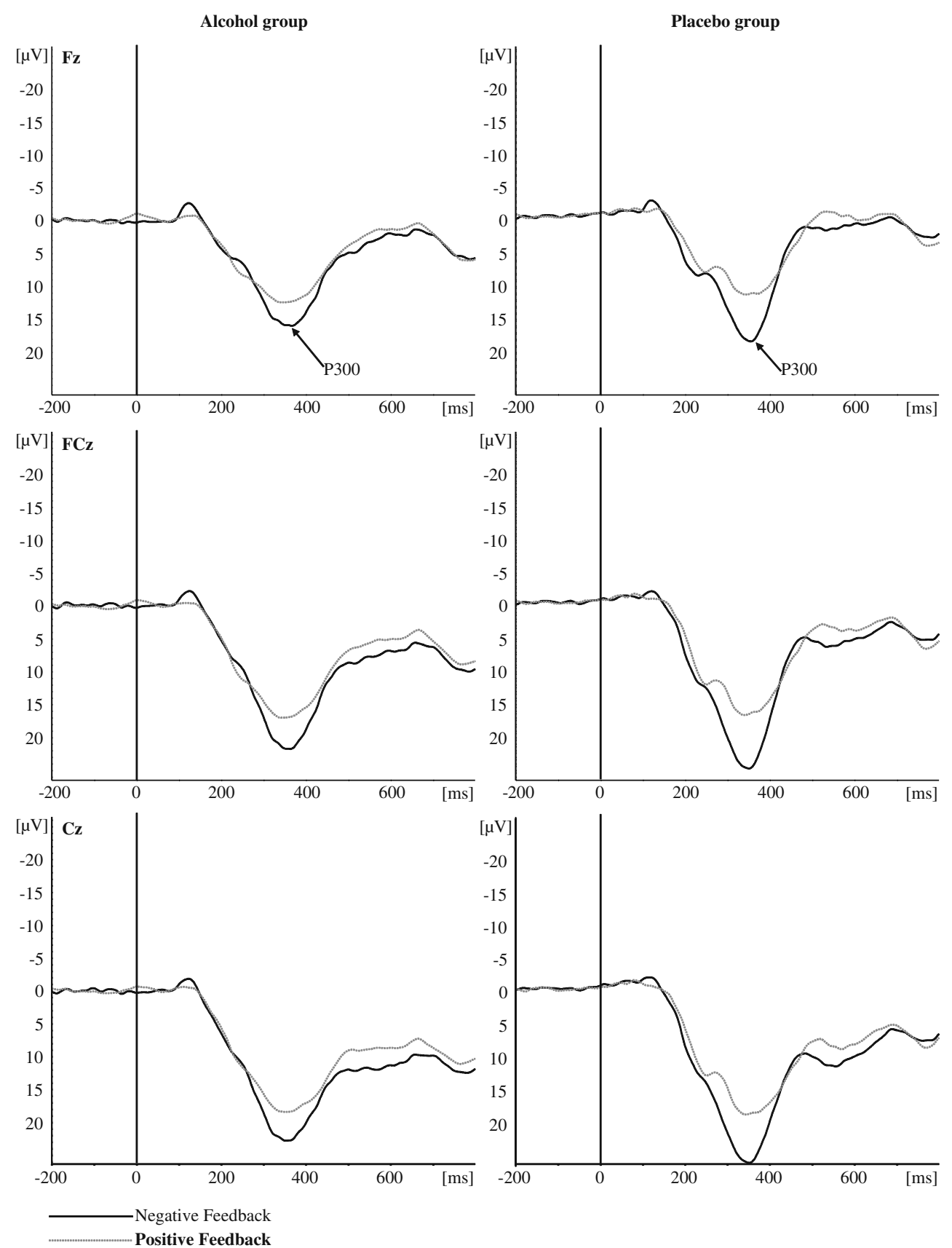

to further process motivationally salient events. Hence, alcohol prevented these participants from building a reinforcement history necessary to guide future behavior.

Importantly, alcohol affected only the in-depth processing of adverse consequences, not positive ones. Subsequently, it is interesting to relate the role of P300 amplitude in feedback processing to that in affective information processing, since both types of stimuli are of affective significance. Hence, P300 amplitude could be a manifestation of emotional appraisal following feedback. This interpretation is in concordance with previous research linking alcohol administration to decreased processing of affective information. For example, in a study of Franken and colleagues (2007), ERPs resulting from watching pleasant, unpleasant, and neutral pictures were investigated in a group of participants receiving a beverage containing a moderate dose of alcohol. Results showed that the brain's response to unpleasant emotional pictures was attenuated after ingestion of a moderate dose of alcohol, suggesting that alcohol selectively reduced processing of unpleasant stimuli. Moreover, Franken et al. (2007) could only demonstrate an effect of alcohol on the ERP index that reflects the later attention-sensitive, more elaborated appraisal of unpleasant stimuli. In a general sense, our results 
Fig. 6 Topographical distribution of the current source density (CSD) of the P300 (300$400 \mathrm{~ms}$ ) associated with losses (i.e., negative feedback; upper row) and gains (i.e., positive feedback; bottom row)

for each group

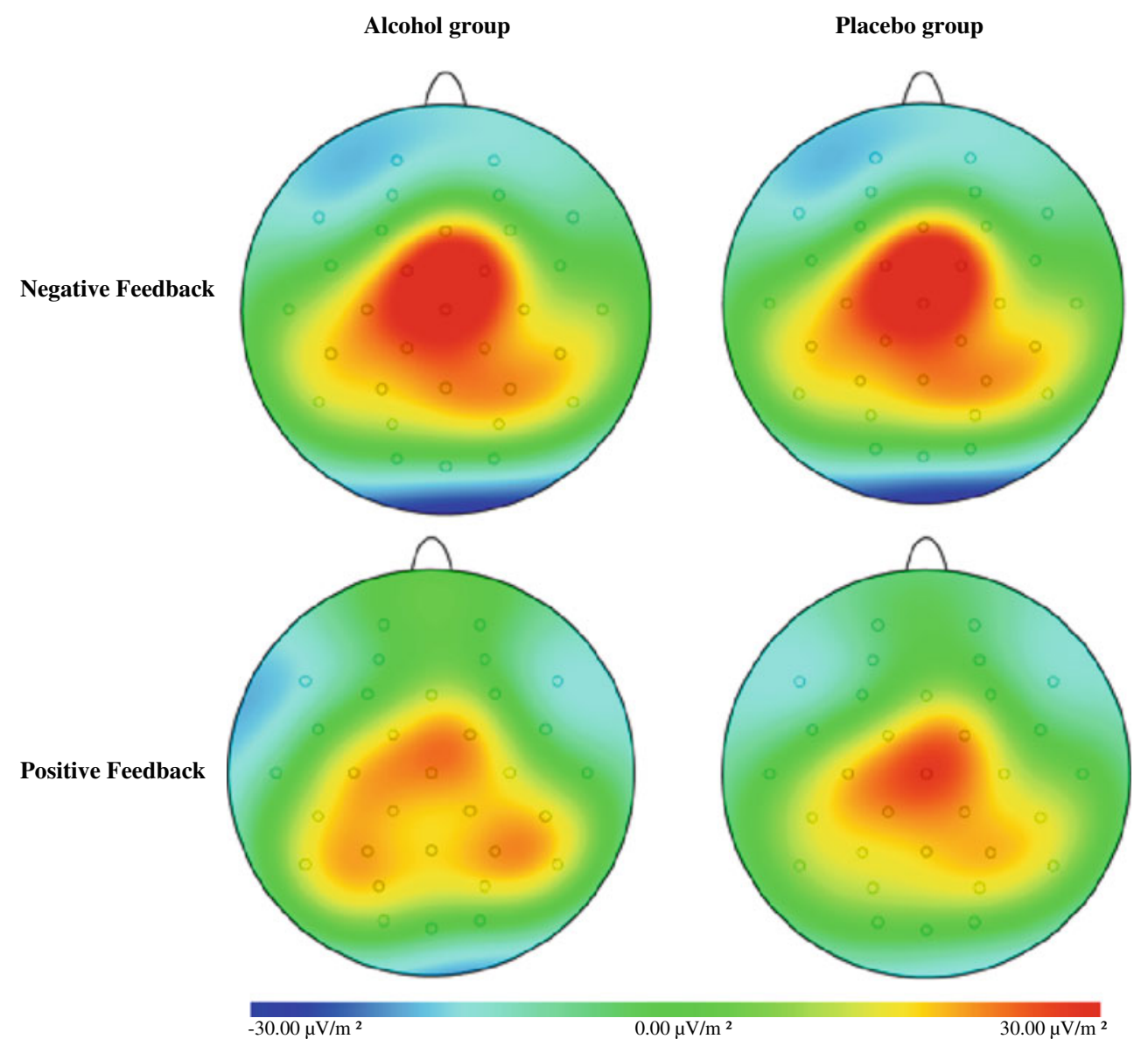

are thus also in line with the notion that alcohol has larger effects on the later, more elaborative and higher-order processes in which factors that affect the allocation of attentional resources come into play in a top-down controlled manner, relative to earlier automatic processes (Fillmore et al. 1999).
Finally, ERPs also correlated with risk-taking behavior during the BART in the alcohol group, where larger FRN amplitudes (i.e., more negative FRN amplitudes) to losses were associated with increased risk-taking. By contrast, larger P300 amplitudes to losses were associated with decreased risk-taking behavior. There were no correlations

Table 4 Spearman correlations between ERPs, risk-taking behavior during the BART, and self-reported personality measures

\begin{tabular}{|c|c|c|c|c|c|c|c|c|c|c|c|c|c|}
\hline & \multirow[t]{2}{*}{ Measure } & \multicolumn{6}{|c|}{ Alcohol group } & \multicolumn{6}{|c|}{ Placebo group } \\
\hline & & $\mathrm{FRN}^{\mathrm{a}}$ & $\mathrm{P} 300^{\mathrm{a}}$ & $\begin{array}{l}\text { p } 1-20 \\
\text { block } 1\end{array}$ & $\begin{array}{l}\text { p } 20-40 \\
\text { block } 2\end{array}$ & $\begin{array}{l}\text { p } 40-60 \\
\text { block } 3\end{array}$ & $\begin{array}{l}\text { Mean } \\
\text { pumps }\end{array}$ & $\mathrm{FRN}^{\mathrm{a}}$ & $\mathrm{P} 300^{\mathrm{a}}$ & $\begin{array}{l}\text { p } 1-20 \\
\text { block } 1\end{array}$ & $\begin{array}{l}\text { p } 20-40 \\
\text { block } 2\end{array}$ & $\begin{array}{l}\text { p } 40-60 \\
\text { block } 3\end{array}$ & $\begin{array}{l}\text { Mean } \\
\text { pumps }\end{array}$ \\
\hline & $\mathrm{FRN}^{\mathrm{a}}$ & & -0.19 & 0.33 & $0.42 *$ & 0.29 & $0.39 *$ & & $-0.42 *$ & 0.07 & -0.02 & 0.09 & 0.03 \\
\hline & $\mathrm{P} 300^{\mathrm{a}}$ & & & -0.33 & $-0.38 *$ & $-0.44 *$ & $-0.41^{*}$ & & & -0.09 & -0.07 & -0.09 & -0.10 \\
\hline BSSS & Total score & -0.20 & -0.17 & -0.04 & 0.02 & 0.07 & 0.03 & 0.28 & 0.17 & 0.35 & -0.18 & 0.01 & 0.13 \\
\hline BIS & Total score & -0.29 & 0.06 & 0.01 & 0.18 & 0.23 & 0.13 & $0.53 * *$ & -0.24 & 0.13 & -0.06 & 0.14 & 0.13 \\
\hline \multirow[t]{2}{*}{ BIS/BAS } & BAS total & -0.07 & 0.23 & -0.24 & -0.21 & -0.23 & -0.28 & -0.31 & 0.13 & $-0.42 *$ & -0.11 & -0.11 & -0.33 \\
\hline & BIS total & 0.08 & -0.04 & -0.20 & -0.08 & -0.02 & -0.10 & 0.22 & 0.16 & 0.23 & 0.29 & -0.05 & 0.16 \\
\hline
\end{tabular}

For all correlations: alcohol group $n=31$; placebo group $n=30$

$B S S S$ brief sensation seeking scale, BIS barratt impulsiveness scale, BIS/BAS BIS/BAS scale

${ }^{*} p<0.05, * * p<0.01$

${ }^{\mathrm{a}}$ Amplitude from difference waveforms at $\mathrm{FCz}$ 
between ERPs and risk-taking behavior in the placebo group. One possible explanation for this finding may be that alcohol-intoxicated participants had difficulty integrating individual instances of gains and losses across multiple trials, leading to unrealistic (overoptimistic) expectations about the chances of winning. Consequently, confrontation with an unexpected loss elicited increased FRNs. Several studies have shown that the FRN amplitude is largest when negative feedback is not anticipated (e.g., Yasuda et al. 2004). Alternative explanations, however, could possibly be that the ERPs may tap a different level of cognitive function than the behavioral measure (i.e., BART) or that either the ERP paradigm or the behavioral measure is not sensitive enough. Possibly, the variation of the scores of the participants in the placebo group may have been too large. Furthermore, no apparent relationships between personality traits and the risk-taking behavior were identified in the present study, which provide evidence to suggest that a direct psychopharmacological effect of alcohol, rather than individual factors, play an important role in moderating risky decision-making.

A number of important issues warrant consideration when interpreting the results of the present study. First, our results should be considered in light of our sample. The sample we recruited was drawn from a young student population with an education level above average and therefore comprises a restricted group. This may restrict the generalizability of our results. In addition, as only men were included in this study, it remains to be clarified whether these findings also apply to women. Future work should investigate the influence of alcohol on risky decision-making in other populations.

Second, we only studied the effect of a moderate alcohol dose, a dose that is relatively low in the context of the levels of alcohol intake typical for the population from which our sample was drawn. Whether higher doses of alcohol would yield similar results or might also affect early feedback processing as measured by the FRN component awaits further research. Future studies that include a range of alcohol doses to produce BACs at or above this level would provide an extension of the present results at more distinct subthreshold intoxication levels.

A third shortcoming concerns our study design. We employed a between-subject design with a single-dose methodology in which each subject received a single dose or placebo, and accordingly the risk-taking data were gathered in just one measurement per subject. However, it should be noted that we found substantial variable betweensubject variability in both ERP patterns and response to the acute alcohol effects. Therefore, a within-subjects design may have provided a stronger demonstration of the acute effects of alcohol and allowed for a dose-response determination - an essential condition for the evaluation of direct pharmacological effects. Future research could extend the current findings by using a within-subjects design.

Another area of concern is the use of the automatic BART version. While there are clear advantages of this version (i.e., use of target score, intended number of pumps), it might be that the automatic response mode version removes an aspects of impulsivity from the response procedure. This may be an important element as impulsivity and inhibitory control are typically thought to be a crucial aspect of substance use and risk-taking (Fillmore and Rush 2002). In addition, the automatic response mode procedure eliminates another factor in decision-making that might be important: the dynamics of the ongoing decision while the balloon is being pumped. Each pump produces an observable change in the context (i.e., balloon gets bigger), which impacts the ongoing behavior. Although we argue that the automatic BART is not biased, it might be this bias that captures the ongoing dynamics of decision-making in real time, including the loss aversion and expectancy valence that may change within a single trial during the pumping phase. In summary, the automatic procedure and the standard BART likely measure different cognitive processes during decisionmaking, with the automatic version having a more analytic mode of processing (Kahneman 2003). This issue is a particularly salient concern because no overall performance differences between groups were observed. Since the two groups' overall choice patterns on the BART were nearly identical, the interpretations of the ERP data must be interpreted with caution. Future studies may further clarify this issue.

One possible way to address the dissociation between the behavior pattern and ERP activation, as discussed above, would be a finer grain analysis of the data separated across the three 20-trial blocks of the BART, as was done with the behavioral data. Unfortunately, a final shortcoming of the present study is that the number of trials in our paradigm was not sufficient to calculate ERPs for each block separately. The ERP data across all balloons already contained substantial noise levels and notorious inter- and intravariability. A finer grain analysis yielded to few data segments, which resulted in even higher noise levels. Consequently, the ERP data needed to be collapsed across the entire task to yield useful data. Future studies may further clarify this issue and should include more trials to perform trial by trial analyses. This would shed light on the question whether FRN is indeed related to short-term adjustments, rather than long-term strategic changes, as hypothesized.

Taken together, despite the acknowledged limitations outlined above, the present results provide important insights into the way alcohol might impact on risky 
decision-making both in the laboratory and in everyday life. Our results indicate that early feedback processing and automatic adaptive behavior are intact under the influence of a moderate dose of alcohol, as reflected in normal FRN amplitudes. More importantly, alcohol-intoxicated individuals display aberrations in later stages of outcome evaluation and controlled adaptive behavior, as reflected in decreased P300 amplitudes in response to negative feedback. The data suggest that people, when intoxicated, may focus more on short-term positive consequences of their actions, ignoring potential harmful consequences on the long term.

Acknowledgments The authors would like to thank Dr. Michael Crowley for providing the Balloon Analogue Risk Task (BART) and for his suggestions for improving the task to make it suitable for electrophysiological measurements. Furthermore, we would like to thank Fanny Ruter for her assistance with data collection.

Declaration on interests The authors have no conflicts of interests regarding the integrity of the reported findings.

Open Access This article is distributed under the terms of the Creative Commons Attribution Noncommercial License which permits any noncommercial use, distribution, and reproduction in any medium, provided the original author(s) and source are credited.

\section{References}

Aklin WM, Lejuez CW, Zvolensky MJ, Kahler CW, Gwadz M (2005) Evaluation of behavioral measures of risk taking propensity with inner city adolescents. Behav Res Ther 43(2):215-228

Balodis IM, MacDonald TK, Olmstead MC (2006) Instructional cues modify performance on the Iowa gambling task. Brain Cogn 60 (2): $109-117$

Bechara A, Damasio AR, Damasio H, Anderson SW (1994) Insensitivity to future consequences following damage to human prefrontal cortex. Cognition 50(1-3):7-15

Bechara A, Dolan S, Hindes A (2002) Decision-making and addiction (part II): myopia for the future or hypersensitivity to reward? Neuropsychologia 40(10):1690-1705

Bickel WK, Marsch LA (2001) Toward a behavioral economic understanding of drug dependence: delay discounting processes. Addiction 96(1):73-86

Breslin FC, Sobell MB, Cappell H, Vakili S, Poulos CX (1999) The effects of alcohol, gender and sensation seeking on the gambling choices of social drinkers. Psychol Addict Behav 13 (3):243-252

Calhoun VD, Pekar JJ, Pearlson GD (2004) Alcohol intoxication effects on simulated driving: exploring alcohol-dose effects on brain activation using functional MRI. Neuropsychopharmacology 29(11):2097-2017

Cantrell H, Finn PR, Rickert ME, Lucas J (2008) Decision making in alcohol dependence: insensitivity to future consequences and comorbid disinhibitory psychopathology. Alcohol Clin Exp Res 32(8):1398-1407

Carver CS, White TL (1994) Behavioral inhibition, behavioral activation, and affective responses to impending reward and punishment: the BIS/BAS scales. J Pers Soc Psychol 67:319333
Christie GJ, Tata MS (2009) Right frontal cortex generates rewardrelated theta-band oscillatory activity. Neuroimage 48(2):415-422

Cooper ML (2002) Alcohol use and risky sexual behavior among college students and youth: evaluating the evidence. J Stud Alcohol Suppl (14), 101-117.

Donkers FC, Nieuwenhuis S, van Boxtel GJ (2005) Mediofrontal negativities in the absence of responding. Brain Res Cogn Brain Res 25(3):777-787

Fein G, Chang M (2008) Smaller feedback ERN amplitudes during the BART are associated with a greater family history density of alcohol problems in treatment-naive alcoholics. Drug Alcohol Depend 92(1-3):141-148

Fillmore MT, Rush CR (2002) Impaired inhibitory control of behavior in chronic cocaine users. Drug Alcohol Depend 66 (3):265-273

Fillmore MT, Vogel-Sprott M (1998) Behavioral impairment under alcohol: cognitive and pharmacokinetic factors. Alcohol Clin Exp Res 22(7):1476-1482

Fillmore MT, Vogel-Sprott M, Gavrilescu D (1999) Alcohol effects on intentional behavior: dissociating controlled and automatic influences. Exp Clin Psychopharmacol 7(4):372-378

Fishbein DH, Eldreth DL, Hyde C, Matochik JA, London ED, Contoreggi $\mathrm{C}$ et al (2005) Risky decision making and the anterior cingulate cortex in abstinent drug abusers and nonusers. Brain Res Cogn Brain Res 23(1):119-136

Franken IHA, Muris P, Rassin E (2005) Psychometric properties of the Dutch BIS/BAS Scales. J Psychopathol Behav Assess 27(1):2530

Franken IH, Nijs IM, Muris P, Van Strien JW (2007) Alcohol selectively reduces brain activity during the affective processing of negative information. Alcohol Clin Exp Res 31(6):919927

Gehring WJ, Willoughby AR (2002) The medial frontal cortex and the rapid processing of monetary gains and losses. Science 295 (5563):2279-2282

George S, Rogers RD, Duka T (2005) The acute effect of alcohol on decision making in social drinkers. Psychopharmacology (Berl) 182(1):160-169

Goyer JP, Woldorff MG, Huettel SA (2008) Rapid electrophysiological brain responses are influenced by both valence and magnitude of monetary rewards. J Cogn Neurosci 20(11):20582069

Gratton G, Coles MG, Donchin E (1983) A new method for off-line removal of ocular artifact. Electroencephalogr Clin Neurophysiol 55(4):468-484

Hajcak G, Holroyd CB, Moser JS, Simons RF (2005) Brain potentials associated with expected and unexpected good and bad outcomes. Psychophysiology 42(2):161-170

Hajcak G, Moser JS, Holroyd CB, Simons RF (2006) The feedbackrelated negativity reflects the binary evaluation of good versus bad outcomes. Biol Psychol 71(2):148-154

Hajcak G, Moser JS, Holroyd CB, Simons RF (2007) It's worse than you thought: the feedback negativity and violations of reward prediction in gambling tasks. Psychophysiology 44 (6):905-912

Halpern-Felsher BL, Millstein SG, Ellen JM (1996) Relationship of alcohol use and risky sexual behavior: a review and analysis of findings. J Adolesc Health 19(5):331-336

Holroyd CB, Krigolson OE (2007) Reward prediction error signals associated with a modified time estimation task. Psychophysiology 44(6):913-917

Holroyd CB, Hajcak G, Larsen JT (2006) The good, the bad and the neutral: electrophysiological responses to feedback stimuli. Brain Res 1105(1):93-101

Hopko DR, Lejuez CW, Daughters SB, Aklin WM, Osborne A, Simmons BL et al (2006) Construct validity of the balloon 
analogue risk task (BART); relationship with MDMA use by inner-city drug users in residential treatment. J Psychopathol Behav Assess 28(2):95-101

Hoyle RH, Stephenson MT, Palmgreen P, Lorch EP, Donohew RL (2002) Reliability and validity of a brief measure of sensation seeking. Pers Ind Diff 32:401-414

Hunt MK, Hopko DR, Bare R, Lejuez CW, Robinson EV (2005) Construct validity of the balloon analog risk task (BART): associations with psychopathy and impulsivity. Assessment 12 (4):416-428

Johnson R Jr (1986) A triarchic model of P300 amplitude. Psychophysiology 23(4):367-384

Kahneman D (2003) A perspective on judgment and choice: mapping bounded rationality. Am Psychol 58(9):697-720

Kamarajan C, Rangaswamy M, Tang Y, Chorlian DB, Pandey AK, Roopesh BN et al (2010) Dysfunctional reward processing in male alcoholics: an ERP study during a gambling task. J Psychiatr Res 44(9):576-590

Lane SD, Cherek DR, Pietras CJ, Tcheremissine OV (2004) Alcohol effects on human risk taking. Psychopharmacology (Berl) 172 (1):68-77

Lau MA, Pihl RO, Peterson JB (1995) Provocation, acute alcohol intoxication, cognitive performance, and aggression. J Abnorm Psychol 104(1):150-155

Lejuez CW, Read JP, Kahler CW, Richards JB, Ramsey SE, Stuart GL et al (2002) Evaluation of a behavioral measure of risk taking: the balloon analogue risk task (BART). J Exp Psychol Appl 8(2):7584

Lejuez CW, Aklin WM, Jones HA, Richards JB, Strong DR, Kahler $\mathrm{CW}$ et al (2003a) The balloon analogue risk task (BART) differentiates smokers and nonsmokers. Exp Clin Psychopharmacol 11(1):26-33

Lejuez CW, Aklin WM, Zvolensky MJ, Pedulla CM (2003b) Evaluation of the balloon analogue risk task (BART) as a predictor of adolescent real-world risk-taking behaviours. J Adolesc 26(4):475-479

Lejuez CW, Simmons BL, Aklin WM, Daughters SB, Dvir S (2004) Risk-taking propensity and risky sexual behavior of individuals in residential substance use treatment. Addict Behav 29(8):16431647

Lejuez CW, Aklin W, Bornovalova M, Moolchan ET (2005) Differences in risk-taking propensity across inner-city adolescent everand never-smokers. Nicotine Tob Res 7(1):71-79

Lemmens P, Tan ES, Knibbe RA (1992) Measuring quantity and frequency of drinking in a general population survey: a comparison of five indices. J Stud Alcohol 53(5):476-486

Leng Y, Zhou X (2010) Modulation of the brain activity in outcome evaluation by interpersonal relationship: an ERP study. Neuropsychologia 48(2):448-455

Luu P, Tucker DM, Derryberry D, Reed M, Poulsen C (2003) Electrophysiological responses to errors and feedback in the process of action regulation. Psychol Sci 14(1):47-53

Martin LE, Potts GF (2009) Impulsivity in decision-making: an eventrelated potential investigation. Pers Ind Diff 46(3):303-308

Mazas CA, Finn PR, Steinmetz JE (2000) Decision-making biases, antisocial personality, and early-onset alcoholism. Alcohol Clin Exp Res 24(7):1036-1040

Meerkerk GJ, Njoo KH, Bongers IM, Trienekens P, van Oers JA (1999) Comparing the diagnostic accuracy of carbohydratedeficient transferrin, gamma-glutamyltransferase, and mean cell volume in a general practice population. Alcohol Clin Exp Res 23(6):1052-1059
Miranda R Jr, MacKillop J, Meyerson LA, Justus A, Lovallo WR (2009) Influence of antisocial and psychopathic traits on decision-making biases in alcoholics. Alcohol Clin Exp Res 33 (5):817-825

Nieuwenhuis S, Yeung N, Holroyd CB, Schurger A, Cohen JD (2004) Sensitivity of electrophysiological activity from medial frontal cortex to utilitarian and performance feedback. Cereb Cortex 14 (7): 741-747

Ortner CN, MacDonald TK, Olmstead MC (2003) Alcohol intoxication reduces impulsivity in the delay-discounting paradigm. Alcohol Alcohol 38(2):151-156

Patton JH, Stanford MS, Barratt ES (1995) Factor structure of the Barratt impulsiveness scale. J Clin Psychol 51(6):768-774

Pleskac TJ, Wallsten TS, Wang P, Lejuez CW (2008) Development of an automatic response mode to improve the clinical utility of sequential risk-taking tasks. Exp Clin Psychopharmacol 16 (6):555-564

Polich J, Criado JR (2006) Neuropsychology and neuropharmacology of P3a and P3b. Int J Psychophysiol 60(2):172-185

Porjesz B, Begleiter H, Bihari B, Kissin B (1987) Event-related brain potentials to high incentive stimuli in abstinent alcoholics. Alcohol 4(4):283-287

Richardson A, Budd T (2003) Young adults, alcohol, crime and disorder. Crim Behav Ment Health 13(1):5-16

Ridderinkhof KR, de Vlugt Y, Bramlage A, Spaan M, Elton M, Snel J et al (2002) Alcohol consumption impairs detection of performance errors in mediofrontal cortex. Science 298(5601):2209-2211

Sato A, Yasuda A, Ohira H, Miyawaki K, Nishikawa M, Kumano H et al (2005) Effects of value and reward magnitude on feedback negativity and P300. Neuroreport 16(4):407-411

Shuper PA, Joharchi N, Irving H, Rehm J (2009) Alcohol as a correlate of unprotected sexual behavior among people living with HIV/AIDS: review and meta-analysis. AIDS Behav 13 (6): 1021-1036

Taylor SP, Chermack ST (1993) Alcohol, drugs and human physical aggression. J Stud Alcohol Suppl 11:78-88

van Meel CS, Oosterlaan J, Heslenfeld DJ, Sergeant JA (2005) Telling good from bad news: ADHD differentially affects processing of positive and negative feedback during guessing. Neuropsychologia 43(13):1946-1954

Vigil-Colet A, Lorenzo-Seva U, Morales-Vives F, Chico E (2007) Assessing extraversion and emotional stability in adolescents: development and validation of a questionnaire. Psychol Rep 101 (2):435-447

Weafer J, Fillmore MT (2008) Individual differences in acute alcohol impairment of inhibitory control predict ad libitum alcohol consumption. Psychopharmacology (Berl) 201(3):315-324

White HR (1997) Longitudinal perspective on alcohol use and aggression during adolescence. Recent Dev Alcohol 13:81-103

Wu Y, Zhou X (2009) The P300 and reward valence, magnitude, and expectancy in outcome evaluation. Brain Res 1286:114-122

Yasuda A, Sato A, Miyawaki K, Kumano H, Kuboki T (2004) Errorrelated negativity reflects detection of negative reward prediction error. Neuroreport 15(16):2561-2565

Yeung N, Sanfey AG (2004) Independent coding of reward magnitude and valence in the human brain. J Neurosci 24(28):6258-6264

Yeung N, Holroyd CB, Cohen JD (2005) ERP correlates of feedback and reward processing in the presence and absence of response choice. Cereb Cortex 15(5):535-544

Zhou Z, Yu R, Zhou X (2010) To do or not to do? Action enlarges the FRN and P300 effects in outcome evaluation. Neuropsychologia 48(12):3606-3613 